Rev. Elev. Méd. Vét. Pays trop., 1967, 20, 1 (21-25).

\title{
La peste équine à type 9 en Afrique centrale Enquête sérologique
}

\author{
par Y. MAURICE et A. PROVOST
}

\begin{abstract}
RÉSUMÉ
Les auteurs ont effectué une enquête sérologıque sur la peste équine à type 9 au Tchad, en République Centrafricaine et au Cameroun. Au terme de celle-ci ils notent la positivité de certains sérums de chevaux, en particulier ceux de la région de Garoua. Dans le contexte régional ce sondage tend à confirmer l'hypothèse d'HOWELL, hypothèse selon laquelle le type 9 serait un virus peu virulent mass très répandu sur le continent africain.
\end{abstract}

L'isolement en octobre 1961 au Tchad par DOUTRE et LECLERCQ (2) du type 9 du virus de la peste équine pose un problème d'épizootiólogie. C'est la première fois que deux souches de ce virus (n० $89 / 61$ et $90 / 61$ dans la classification d'ONDERSTEPOORT), sérologiquement identiques à la souche $7 / 60$ responsable de la flambée épizootique du Proche-Orient, étaient isolées en Afrique.

On se souvient que ces deux souches ont été isolées à partir de deux étalons anglo-arabes Importés de France par voie aérienne directe sans escale le 16 septembre 1961 pour assurer la remonte dans un haras du Tchad. Dès leur arrivée, ces deux animaux furent emmenés par camion au service vétérınaire de Fort-Lamy et placés en écurie. Les premiers signes cliniques apparurent respectivement le 27 ef le 30 septembre, soit 9 et 12 jours après l'arrivée des étalons: les animaux succombèrent après 5 et 6 jours de maladie.

Depuis, aucun cas de peste équine n'a été signalé au Tchad.

Certes, la peste équine est depuis longtemps incriminée comme étant une composante de la pathologie équine en Afrique Centrale mais elle n'est que rarement signalée cliniquement. Toutefois en avril 1961, deux chevaux de la Garde Territoriale Tchadienne ef un étalon appartenant au Directeur du Service de l'Élevage du Tchad présentèrent des symptômes évoquant ceux de la peste équine. Les isolements de virus tentés à cette époque permirent l'obtention d'un virus dont l'identification ne put être menée à bien.

Ces rappels étant exposés, on est en droit de se poser deux questions :

- La peste équine à type sérologique 9 estelle une maladie depuis longtemps implantée en Afrique Centrale, évoluant sur une population équine semi-résistante ef qui ne manifeste son infection qu'en de rares occasions? En ces circonstances les deux étalons morts en 1961 seraient les « révélateurs » d'une infectıon occulte. Sı cette hypothèse est exacte, la trace sérologique de l'infection à virus 9 doit persister dans les sérums des chevaux autochtones sous forme d'anticorps.

- La peste équine à type 9 n'est-elle pas au contraire qu'un épiphénomène sans lendemain, le virus ayant été fortuitement importé et se montrant dans l'incapacité d'infecter d'autres équidés par manque du vecteur approprié ?

Ces questions en attirent une troisième : si la réponse à la première question est positive, on pourrait émettre I'hypothèse que l'Afrique Centrale puisse être l'un des réservoirs de virus du type 9 , type sérologique nouvellement reconnu. 
Si la première réponse est négative, on peut se demander si au contraire le Tchad n'a pas été contaminé à partir du Proche-Orient.

Seul un sondage sérologique pouvait permetıre de se faire une opinion. II a été entrepris et mené à bien en adoptant la réaction d'inhibition de l'hémagglutination comme moyen d'investigation sérologique.

\section{I. - MATÉRIEL ET MÉTHODES}

\section{A) Matériel.}

\section{Le virus :}

Les troisième et quatrième passages sur cerveau de souriceau de la souche de type 9 isolée par DOUTRE ef LECLERCQ (1962) (2) ont servi de matériel de départ.

\section{$2^{\circ}$ L'antigène :}

L'antigène est préparé à partir de cerveaux de souriceaux nouveau-nés morts de peste équine ou prélevés au stade final de la paralysie après inoculation de la souche par voie intracérébrale.

\section{Les globules rouges :}

Des hématies de cheval ont été utılisées.

\section{Les sérums :}

Les sérums examinés concernent 135 chevaux d'Afrique Centrale vivants dans des régions géographiques différentes :

- 33 sérums de chevaux provenant des écuries de la Garde nationale de Fort-Lamy, Tchad.

- 10 sérums de chevaux de la région de Moussoro, c'est-à-dire du nord du Tchad.

- 12 sérums de chevaux de la région de Mao, c'est-à-dire du nord du Tchad.

- 17 sérums de chevaux de la région d'Ati, c'est-c̀-dire de l'est du Tchad.

- 20 sérums de chevaux de la région de Fort-Archambault, c'est-c̀-dire du sud du Tchad.

- 9 sérums de chevaux du club hippique de Bangui (République centrafricaine).

- 5 sérums de chevaux de la région de N'Gaoundéré (Cameroun).

- 29 sérums de chevaux de la région de Garoug (Cameroun).

\section{B) Techniques.}

La technique de la réaction d'inhibition de I'hémagglutination en matière de peste équine a été décrite par PAVRI (6) en 1961, puis par PAVRI et ANDERSON en 1963 (7). Plus récemment MAURICE ef PROVOST (5) ont étudié le rôle des différents paramètres entrant dans la réaction, afin d'apprécier les fausses agglutinations positives dues à l'actıvité hémagglutinante de certaines protamines. II n'est pas question ici de reprendre cette étude. Seule sera décrite la technique de préparation de l'antigène, technique qui n'a été que mentionnée dans l'article précédent.

\section{L'antigène.}

L'antigène saccharose-acétọne-protamine a été employé. Cet antigène a été préparé en utılisant la méthode employée à l'East African Virus Research Instıtute. Cette technique est la suivante :

- Prélèvement de matière cérébrale :

Les souriceaux non inoculés (antigènes témoins) ou ceux parvenus au stade final de la paralysie par le virus de la peste équine sont sacrifiés au chloroforme ou à l'éther sous cloche. Lorsque la mort provoquée par le virus spécifique est survenue peu de temps auparavant les cervecux sont également recueillis stérilement, placés à - $15^{\circ} \mathrm{C}$ et utilisés presqu'aussitôt pour la préparation de l'antigène.

- Préparation de l'antigène saccharose-acétone-protamine.

- 1er jour : La matière cérébrale est décongelée d̀ température ordinaire. Dans un broyeur on place 4 grammes auxquels on ajoute $16 \mathrm{ml}$ d'une solution de saccharose à 8,5 p. 100. L'ensemble est broyé et centrifugé à grande vitesse à $+4^{\circ} \mathrm{C}$.

Avec une pipette de $10 \mathrm{ml}$ on dépose doucement $9 \mathrm{ml}$ de suspension dans deux pots à centrifuger contenant $180 \mathrm{ml}$ d'acétone pure refroidie à $-30^{\circ} \mathrm{C}$. On verse lentement et progressıvement. Au bout d'un certain temps la matière cérébrale agglomérée remonte en surface. On bouche au cooutchouc ef on laısse 10 minutes à température ordinaire avec agitations fréquentes et vigoureuses en desserrant les bouchons entre les agitations. On centrifuge légèrement au froid et on vide l'acétone sans entraîner le culot. 
On ajoute à nouveau $180 \mathrm{ml}$ d'acétone pure eton laisse une heure d̀ $0^{\circ} \mathrm{C}$. Le sédıment est alors pulvérisé en se servant d'un pilon. On centrifuge ensuite pendant $\mathrm{c}$ Inq minutes à $+4{ }^{\circ} \mathrm{C}$ à 1.000 tours/ minute, et on rejette l'acétone surnageañt.

On reprend le culot par $180 \mathrm{ml}$ d'acétone dans chaque pot. La centrifugation est faite pendant cing minutes d̀ 1.000 tours par minute d̀ $4^{\circ} \mathrm{C}$. On ne rejette pas toute l'acétone pour pouvoir mélanger les culots. On centrifuge ensuite à 2.000 tours/minute pendant 5 minutes à $4{ }^{\circ} \mathrm{C}$. L'acétone surnageant est aspiré et le sédiment est placé dans un flacon où l'on réalise le vide pour dessécher la poudre. A l'arrêt de la pompe, le vide est cassé avec précaution.

La remise en suspension de la poudre est faite dans une solution de chlorure de sodium à 0,9 p. 100 dont la quantité est les $2 / 5$ du volume de la suspension en saccharose soit $7,2 \mathrm{ml}$ dans le cas présent. On agite vigoureusement avec des perles de verre ajoutées en quantité modérée. On conserve le flacon à $+4^{\circ} \mathrm{C}$ pendant l'après midi et la nuit ou simplement l'après midi et une partie de la soirée.

- $2^{e}$ jour : La protamine est diluée en sérum physiologique à rasson de $50 \mathrm{mg}$ de protamine pour $1 \mathrm{ml}$ de solution physiologique. La dissolutıon demande cinq à dix minutes à température ordinaire en écrasant la poudre, on laisse le flacon à $4^{\circ} \mathrm{C}$ pendant 15 minutes pour achever la dissolution. Cette solution de protamine ainsi préparée extemporanément est ajoutée à l'antigène préparé la veille de façon à avoir $5 \mathrm{mg}$ de protamine par $\mathrm{ml}$ d'antigène. On laisse le mélange d̀ $+4^{\circ} \mathrm{C}$ pendant une demi-heure en agitant souvent ef vigoureusement, et on centrifuge à 2.500 tours pendant 15 minutes à $+4^{\circ} \mathrm{C}$. Le surnageant constitue l'antigène prêt à être utilısé.

\section{$2 \circ$ Les globules rouges.}

On utilise des globules rouges de cheval en suspension à 0,5 p. 100 en solution tampon. Après addition d'un volume égal d'antigène la réaction doit avoir lieu à $\mathrm{pH} 6,4$. Pour que la réaction ait lieu à $\mathrm{pH} 6.4$ la solution tampon doit être préparée en mélangeant $16 \mathrm{ml}$ d'une solution $n^{0} 1$ ef $34 \mathrm{ml}$ d'une solution $n^{\circ} 2$. ces solutions 1 et 2 ayant la composition ci-dessous :
Solution 1

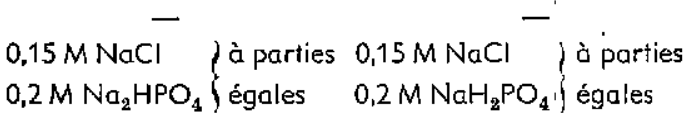

Par précaution il est utile d'effectuer le titrage de l'antigène à des $\mathrm{pH}$ de $6,3,6,4$ et 6,5 pour être sur de travailler au $\mathrm{pH}$ optımum de la réaction. Les compositions des tampons à utiliser pour mettre en suspension les globules de cheval sont Indiquées dans l'article fondamental de CLARKE ef CASALS (1) relatif à la préparation des antigènes des arbovirus.

\section{Les sérums.}

- Le sérum hyperimmun de référence utilisé est préparé sur cobayes par injections intrapéritonéales répétées de $1 \mathrm{ml}$ d'une suspension de 10 p. 100 d'encéphale de souriceau mort de peste équine d̀ type 9 .

- Le sérum négatif de référence est un sérum de cheval de France, pays indemne de peste équine.

- Tous les sérums sont traités systématiquement au kaolin lavé aux acides pour éliminer les inhibiteurs non spécifiques. La technique est la sulvante: $1 \mathrm{ml}$ de sérum est mis en contact avec $4 \mathrm{ml}$ de tampon borate $\mathrm{pH} 9$ et $5 \mathrm{ml}$ d'une suspension de kaolin de 25 p. 100 . L'ensemble est maintenu à température ordınaire pendant vingt minutes avec agitations fréquentes. On centrifuge ensuite à la température ordinaire à 2.500 tours/minute pendant trente minutes. Le surnageant représente donc le sérum dilué au $1 / 10^{\mathrm{e}}$.

40 La réaction.

o) Titrage de l'antigène:

L'antigène est tıtré en effectuant la récction à $\mathrm{pH}$ 6.4, pH pour lequel l'agglutination est maximum. Les dilutions d'antigène sont faites en tampon albumine à 0,4 p. 100 ef les globules rouges de cheval sont en suspensıon à 0,5 p. 100. La réaction est fate sur plaque plexiglass sous le volume de $0,2 \mathrm{ml}$ d'antıgène et $0,2 \mathrm{ml}$ de globules rouges, ou sous le volume de $0,4 \mathrm{ml}$ pour chaque réactif. Les résultats sont identiques, la lecture étant simplement plus rapide sous le volume de $0,2 \mathrm{ml}$ de chaque réactif. Le résultat est lu après une incubation de 45 à 60 minutes à $37^{\circ} \mathrm{C}$. 
b) La réaction d'ınhıbition de l'hémagglutination :

La réaction est effectuée à $\mathrm{pH}$ 6,4. Les dilutions d'antigène sont faites en tampon d'albumine à $0,4 p .100$, et les globules rouges de cheval à 0,5 p. 100 sont ajoutés au mélange antigènesérum après une incubation d'une nuit à $4{ }^{\circ} \mathrm{C}$. On opère sur plaque de plexiglass sous le volume de $0,2 \mathrm{ml}$ d'antigène (4 unités antigéniques), $0,2 \mathrm{ml}$ de sérum et $0,4 \mathrm{ml}$ de globules rouges. Le résultał 'est lu après une incubation d'une heure à $37^{\circ} \mathrm{C}$.

\section{II. - RÉSULTATS ET DISCUSSION}

\section{Résultats.}

L'analyse qualitative de 135 sérums de chevaux a donné les résultats mentionnés sur le tableau I ; 39 sérums sur 135 présentent des anticorps contre le type 9 .

TABLEAU NOI

\begin{tabular}{|c|c|c|c|}
\hline Pays & Iracalité & $\begin{array}{l}\text { Nombre de } \\
\text { sérrums étudiés }\end{array}$ & $\begin{array}{l}\text { Nombre de sérums } \\
\text { présentant des anticorps } \\
\text { contre le type } 9\end{array}$ \\
\hline Tehad & $\begin{array}{l}\text { Fort-Lemy } \\
\text { Ati } \\
\text { Mao } \\
\text { Moussoro } \\
\text { Fort-Archambault }\end{array}$ & $\begin{array}{l}33 \\
17 \\
12 \\
10 \\
20\end{array}$ & $\begin{array}{l}9 \\
3 \\
1 \\
1 \\
0\end{array}$ \\
\hline $\begin{array}{l}\text { République } \\
\text { Centrafrucaine }\end{array}$ & Banguz & 9 & 0 \\
\hline Cameroun & $\begin{array}{l}\text { N'Gaoundéré } \\
\text { Garoua }\end{array}$ & $\begin{array}{r}5 \\
29\end{array}$ & $\begin{array}{r}0 \\
25\end{array}$ \\
\hline
\end{tabular}

\section{$2^{\circ}$ Discussion.}

On sait que la réaction d'inhibition de l'hémagglutination avec le virus de la peste équine est spécifique de type mais qu'il existe une parenté antigénique entre le type 9 et le type 6 (PAVRI ef ANDERSON, 1963) (7). C'est pourquoi les sérums de Fort-Lamy, Mao, Moussoro, Ati, Fort-Archamboult, Bangui et Garoua ont été étudiés en utilisant la même réaction d'inhıbıtıon de l'hémagglutination avec un antigène préparé à partır de cerveaux de souriceaux morts de peste équine à type 6. La technique de préparation de cet antigène est la même que la précédente et les deux virus ont un titre hémagglutınant identique. II a été ainsi constaté que :

- 2 sérums sur 33 de Fort-Lamy présentent des antıcorps ınhıbant l'hémagglutination contre le type 6 . Ces deux sérums sont d'ailleurs également positifs vis-à-vis du type 9.

- 1 sérum de Mao est positif vis-à-vis du type 6 mais il s'agit du sérum également positif vis-d̀-vis du type 9 .

- Aucun sérum de Moussoro, Ati, Fort-Archam- bault et Bangui ne présente d'anticorps inhibant I'hémagglutination contre le type 6 .

- 16 sérums de Garoua sont positifs vis-à-vis du type 6 . Parmi ces 16 sérums, 14 sont positifs vis-c̀-vis du type 9.

Il ne sera pas tiré de conclusion pour ce qui est des sérums positifs vis-à-vis à la fois du type 6 et du type 9 mais on peut affirmer que 7 sérums sur 33 de Fort-Lamy, 1 sérum sur 10 de Moussoro et 11 sérums sur 29 de Garoua présentent des antıcorps signant la présence du type 9.

\section{III. - CONCLUSION}

Les résultats donnés par ce sondage permettent de conclure que les cas de peste équine da type 9 observés dans la capitale du Tchad ne sont probablement pas limités à la seule région de FortLamy. Il est vraisemblable, et cette étude confirme I'hypothèse et les observations de HOWELL (1962) (3), que les souches appartenant au groupe immunologique 9 sont des souches de faible virulence, ne provoquant sur les effectifs équins 
locaux que des infections bénignes voire inapparentes.

Il est possible que le plus grand nombre de sérums positifs en provenance de Fort-Lamy et surtout de Garoua reflète une plus grande pullulation du vecteur, elle-même dépendante de la pluviométrıe.

Les chevaux de Mco, Moussoro et Ati, villes à plus faible pluviosité que les précédentes, auraient ainsi moins de chance d'être exposés à l'infection. On peut être à priori surpris de la négativité des sérums de Bangui. En fait les chevaux dont il s'agit ont été achetés dans le Nord du Tchad et maintenus depuis plusieurs années à Bangul. Leur sérologie retrace celle du Sahel (Moo, Moussoro) dont ils sont origınaires et non celle d'une région à forte pluviosité (Garova) ; doit-on en conclure à la non-infection du Sud de la R. C. A. par le virus de type 9 ; c'est une possibilité qui n'est pas à exclure sı l'on se souvient que le cheval est d'introduction récente dans cette région.

\section{Institut d'Elevage et de Médecine Vétérinaire des Pays tropicaux. \\ Laboratore de Farcha, Fort-Lamy. Tchad}

\section{SUMMARY}

Horse Sickness caused by type 9 virus in central Africa. Serological survey

A serological survey on Horse Sickness caused by type 9 virus was carried out by the authors in Chad, in Central African Republic and in Cameroon. According to the result of this survey, some sera of horses, mostly in the Garoua area, were shown to be positive. Inside the prospected area, this survey tended to confirm the idea of HOWELL, who had suggested that the type 9 would be a less virulent virus, but very widespread throughout African continent.

\section{RESUMEN}

La peste equina causada por el virus del tipo 9 en Africa central. Encuesta serológica

Se efectuó una encuesta serológica sobre la peste equina causada por el virus del tipo 9 en Chad, en la República Centroafricana y en Camerún. Según los resultados se nota la positividad de algunos sueros de caballos, particularmente de los de la región de Garua.

En dicha región este estudio va confirmando la hipólesis de HOWELL, es decir que el tıpo 9 seria un virus poco virulento pero muy encontrado en el continente africano.

\section{BIBLIOGRAPHIE}

1. CLARKE (D. H.) ef CASALS (J.). - Techniques pour l'hémagglutination ef l'inhibition de l'hémagglutination avec les arbovirus. Amer. J. Trop. Med., 1958, 7, 561.

2. DOUTRE (M. P.) et LECLERCQ (A.). Existence du type 9 du virus de la peste équine au Tchad. Rev. Elev. Med. Vet. Pays Irop., 1962, 15 (3), 241-245.

3. HOWELL (P. G.). - Isolement et identification de nouveaux types antigéniques du virus de la peste équine. Onderstep. J. Vet. Res., $1962,29(2), 139$.
4. HOWELL (P. G.) ef ERASMUS. - Confribution à l'étude du virus de la peste équine africaine. Bull. Off. int. Epiz., 1963, 60, 883-887.

5. MAURICE (Y.) et PROVOST (A.), - La réaction d'hémagglutination ef d'inhibition de l'hémagglutination avec le virus de la peste équine. Les limites de son interprétation. Rev. Elev. Méd. Vét. Pays trop., 1966, 19 (4), 439-50.

6. PAVRI (K. M.) et ANDERSON (C. R.). Réaction d'inhibition de l'hémagglutination avec différents types du virus de la peste équine africaine. Ind. J. Vet. Sci., 1963,33 (3), 113-117. 